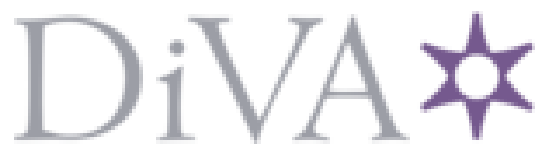

http://www.diva-portal.org

This is the published version of a paper published in Gerontechnology.

Citation for the original published paper (version of record):

Tsertsidis, A. (2021)

Identifying digital solutions for people with dementia (PwD): Lessons learned from a Swedish dementia care residence

Gerontechnology, 20(2): 1-14

https://doi.org/10.4017/gt.2021.20.2.19.05

Access to the published version may require subscription.

N.B. When citing this work, cite the original published paper.

Permanent link to this version:

http://urn.kb.se/resolve?urn=urn:nbn:se:oru:diva-92043 


\title{
Identifying digital solutions for people with dementia (PwD): Lessons learned from a Swedish dementia care residence
}

\author{
Antonios Tsertsidis $\mathrm{PhD}^{\mathrm{a}, *}$ \\ ${ }^{a}$ Department of Informatics, Örebro University, SE-701 82 Örebro, Sweden; *Correspond- \\ ing author: antonios.tsertsidis@oru.se
}

\begin{abstract}
Background: With the ongoing rise of the elderly population and the subsequent number of dementia cases, digital technologies are often appearing to support people with dementia in their daily living activities. However, the majority of scientific literature tends to focus mostly on these digital technologies as sole solutions.

Objective: Real-life implementations can be successful if we have a better understanding of the social, environmental, and technical aspects combined. Hence, this article reports a case study conducted in a Swedish dementia care residence to identify possible digital technologies' needs.

Method: A case study was conducted in a Swedish dementia care residence.

Results: The results show that even though digital technologies are crucial in supporting both staff and residents, digital technologies alone cannot address the complex needs identified within the residence.

Conclusion: For the digital technologies to be effective, they need to be integrated into the dementia care residence's work processes and the capabilities of the current design of the property hosting the residence. Thus maintaining a socio-technical rather than a techno-centric perspective.
\end{abstract}

Keywords: Dementia, technology, care residence, needs, lessons learned

\section{INTRODUCTION}

Dementia is a disease, causing a decline in mental ability severe enough to interfere with daily life (Alzheimer's Association, n.d.). It has been predicted that worldwide dementia cases will increase from 66 million in 2030 to 115 million in 2050 (Prince et al., 2011). As the number of people living with dementia increases, the research on digital technologies that can support them and increase their quality of life is growing (Meiland et al., 2017; Lorenz et al., 2019). Previous research shows that the quality of life for people with dementia can be enhanced or maintained by digital technologies supporting independence, safety, and autonomy (Cahil et al., 2007; Tsertsidis, 2020).

There is evidence that digital technologies can facilitate social inclusion, help families, and support healthcare organisations (Rashidi and Mihailidis, 2012). Digital technologies include assistive technologies, ambient assisted living technologies, telehealth and monitoring systems, robots, and other information and communication technologies (Tsertsidis et al., 2019). A literature review on involving people with dementia in the development of digital technologies shows that in the past, people with dementia were an excluded group due to the stigma attached to dementia and other attributed difficulties (Span et al., 2013). However, Span et al. (2013) argue that cognitive impairment is no reason to exclude people with dementia from digital technologies development. Involving people with dementia could have empowering effects on this group of users (Stoukides, 2008; Span et al., 2013). Identifying user needs is an essential phase in the early stages of every design project (Blasco et al., 2016).

Several reviews (Meiland et al., 2017; Lorenz et al., 2019; Span et al., 2013; Suijkerbuijk et al., 2019; Holthe et al., 2018) describe how people with dementia are involved during different stages of the development of digital technologies. According to a literature review by Suijkerbuijk et al. (2019), people with dementia are mostly involved in the generative or evaluative development stage. This is when the first ideas of a new design are constructed or when the prototypes are evaluated. Only nine (Lazar et al., 2017; Lopes et al., 2016; Holbø et al., 2013; Lindsay et al., 2012; van Rijn et al., 2010; Mor'an and Meza Kubo, 2009; Hagethorn et al., 2008; Lee and Dey, 2007; Cohene et al., 2005) of 49 studies included in the review considered the pre-design stage, which aims at understanding people's experiences in the context of their lives (Suijkerbuijk et al., 2019). In all these 
studies, digital technology is decided in advance, and the focus is on how it fits the target group's life. Recent research shows that the use of digital technologies in residential care increases residents' independence, reducing caregivers' burden (Mortenson et al., 2018). That said, only four (Lazar et al., 2017; Lindsay et al., 2012; Mor'an and Meza Kubo, 2009; Cohene et al., 2005) of the nine studies on the pre-design stage address needs of people with dementia living in dementia care residences (Suijkerbuijk et al., 2019).

Since the technology is pre-determined in all previous studies right at the beginning, the focus is often on the technology itself and its functionality. Researchers state that maintaining a techno-centric product perspective does not allow capturing needs that emerged in complex social environments (Östlund et al., 2015; Eason et al., 2015). Furthermore, social aspects appear as the most common reasons why new technologies are still not adopted in today's elderly care (Vichitvanichpong et al., 2014; Ertner, 2019; Oishi et al., 2019). It is argued that real-life implementations can be successful if we have a better understanding of the social, environmental, and technical aspects combined (Kristofferson et al., 2014; Kolkowska et al., 2016; Frennert, 2020). For this reason, we take a broader, more holistic perspective on the needs regarding digital technologies that can support people with dementia in their daily life. Therefore, we include the social and environmental factors necessary to make the technology work in real-life settings. Our study focuses on the pre-design stage to understand the needs of people with dementia in the context of their lives. This study aims to identify possible digital technologies to cover the needs of people with dementia regarding daily living activities within a dementia care residence. The study is conducted at a dementia care residence located in a Swedish municipality, where the residents were already at a severe/late stage of dementia. The rest of the article provides an overview of scientific literature regarding people with dementia's participation in identifying technological needs. Then it describes its research design, the case study, and the data collection and analysis. The results are then presented, and lastly, the authors provide the conclusions and discussions of this article.

\section{Related RESEARCH}

People with dementia face difficulties identifying and expressing their needs as regards technology development (Span et al., 2013). Such difficulties may vary from unclear and empty speech to decreased vocabulary, flawed grammatical reasoning, changes in word association patterns, and disorganised discourse (Hubbard et al., 2002). While dementia is a life-terminating disease, a person can live with the disease on an average of
8 to 10 years (Alzheimer's Association, n.d.). In the beginning, its effects are considered mild to moderate, but that does not stop its progression, which eventually leads to dementia, majorly affecting a person's cognitive abilities.

The research focusing on understanding how digital technologies can support people with dementia in their daily life and fit the context and experiences of their lives is limited. The four studies included in the Suijkerbuijk et al. (2019) review described the involvement of people with dementia living in dementia care residences in collecting needs before the digital technology is in place (Lazar et al., 2017; Lindsay et al., 2012; Mor'an and Meza Kubo, 2009; Cohene et al., 2005) focus exclusively on one type of technological aid: a platform for communication and social sharing (Lazar et al., 2017), GPS for navigation (Lindsay et al., 2012), cognitive stimulation (Mor'an and Meza Kubo, 2009), and Lifelogging system (Cohene et al., 2005). The participants in the studies above reportedly had mild to moderate stages of dementia. Informal caregivers were involved in three of the four studies. Lazar et al. (2017) and Moran and Meza-Kubo (2009) focus on understanding interactions between people with dementia and their caregivers to design suitable digital technologies. Lazar et al. (2017) analyse what social sharing means for people with dementia and conclude that new digital technologies for social sharing are part of "socio-material arrangements" and of the process of meaning-making in this context. Moran and Meza-Kubo (2009) propose a set of design principles for developing a cognitive support system based on an analysis and categorisation of interactions between individuals with dementia and their caregivers.

Lindsay et al. (2012) and Cohene et al. (2005) focus on methodological aspects of involving people with dementia in the pre-design stage of technology development. The authors argue that involving people with dementia is a challenge because of their limited ability to communicate and express themselves; therefore, it is beneficial to involve caregivers in data collection sessions. According to the authors, caregivers aid communication and make their spouses feel comfortable. However, Lindsay et al. (2012) point out that there is a risk that the caregivers take over and their needs become more important than those of people with dementia.

None of the studies focused on understanding people's daily living activities with dementia within a dementia care residence or studied which digital technologies could best address the needs experienced in this setting. There are different examples of digital technologies that may support people with dementia and their caregivers in care residence settings. According 
to a review conducted by Lorenz et al. (2019), the most common digital technologies used in this context are digital technologies with therapeutic effects such as pet robots or simulated presence therapy. Other examples of therapeutic 'entertainment and reminiscence' aids are photo albums, music, games, films, or karaoke-style apps. Memory and safety aids are also frequently used in these settings. Examples of such aids are sensor mats and movement sensors. These aids can set off alarms if people with dementia get up and start moving. When used correctly, these aids can reduce the need to check on people at night and potentially disturb their sleep.

According to the literature, there are different reported methods for involving people with dementia in different digital technologies development stages. For instance, Span et al. (2013) report interviews as the most common method, while Suijkerbuijk et al. (2019) report interviews and observations as the most commonly used methods. They also argue that there is a lack of specific knowledge of appropriate methods and materials for people with dementia's active involvement in developing digital technologies. The problem is even bigger regarding people with advanced dementia. For example, in the review by Suijkerbuijk et al. (2019), the reported stages of dementia were from mild to severe, but only 7 out of 49 studies included people with severe dementia. This is rather surprising considering that Whitlatch and Menne (2009) report that even people with advanced dementia can express their needs. No studies included in the review by Span et al. (2013) included people with severe dementia, which also was noted by Meiland et al. $(2017$, s.4), who stated that "...people with more severe dementia are less often included in the development of digital technologies". All participants in our study were already in the late stages of dementia. Sjölinder et al. (2017) suggest that when individuals cannot express themselves and their cognitive abilities have severely declined, researchers may use caregivers' or relatives' voices. The caregivers assume the role of proxies, who act as mediators, meaning that they speak on behalf of the study participants (Gruber-Baldini et al., 2012) with dementia. According to Liu et al. (2018), the degree of agreement between caregivers and dementia clients, suggests that caregivers can accurately respond on behalf of dementia clients regarding technology acceptance. Thus, the needs are voiced through another person with a deep insight into the study participants' circumstances and wishes. We have applied this method in our study.

\section{RESEARCH DESIGN}

This study was conducted as an interpretative case study (Denscombe, 2014) at a dementia care residence in a municipality in Sweden. Interpretive research provides flexibility regarding the reformulation of the researchers' prior knowledge and understandings during the research process. In that sense, data generation and data analysis are interconnected (Schwartz-Shea and Yanow, 2013). One significant difference between the previous studies (Meiland et al., 2017; Lorenz et al., 2019; Span et al., 2013; Suijkerbuijk et al., 2019; Holthe et al., 2018) and ours, is that technology is not chosen in advance but selected to address the actual needs elicited based on an understanding of daily living activities within a dementia care residence. Hence, addressing the actual needs of people with dementia. Another difference is that the participants were already in the late stages of dementia.

\section{Case setting}

Health and social care for the elderly are essential parts of Swedish welfare policy. Municipal taxes and government grants fund elderly care. Currently, 20 percent of Sweden's inhabitants have passed the standard retirement age of 65 (Eurostat, n.d.), and this number is expected to rise to 23 percent by 2040 . Alongside the rapid increase of the elderly population, there is an additional increase in people who have dementia. In Sweden, the National Board of Health and Welfare (Socialstyrelsen, 2018) reports that 150,000 elderly live with dementia and that the number will rise to 200,000 in 2030. This increase in the ageing population, together with the increase in dementia patients, brings additional challenges to the staff's workloads responsible for taking care of them. Digital technologies are thus seen as a means for reducing some of that workload. Sweden has introduced digital technologies to (1) enable disabled people to be more independent and (2) increase the ease and safety by which certain tasks can be performed. The assessment of which technology to use is based on a standardized method for assessing needs, called IBIC (Lundälv, 2017), which translates to "individual needs in the centre". This rapid use and implementation of digital technologies are also in line with Sweden's digitalization strategy (Regerinskasliet, n.d.). However, the National Board of Health and Welfare reports that it is important to include users of such technologies in the implementation so that their needs are accurately covered (Socialstyrelsen, 2017). The same report states that the elderly with dementia face potential risk in achieving an active role in developing digital technologies due to their dementia-related challenges.

\section{Case study}

The dementia care residence was housed on the third floor of a housing complex in the expansive and modern part of a middle-sized Swedish city (block). The same building hosts a health centre, 
Table 1. Data collection stages and their characteristics.

\begin{tabular}{lcc}
\hline Date & Type of data collection & $\begin{array}{c}\text { Number of } \\
\text { participants }\end{array}$ \\
\hline 13 March 2019 & Focus group interview - staff & 12 \\
\hline 10 April 2019 & Focus group interview - relatives & 4 \\
\hline 15 April 2019 & $\begin{array}{c}\text { Observations of the environment } \\
\text { and areas of the residence }\end{array}$ & $\mathrm{N} / \mathrm{A}^{1}$ \\
\hline 15 April 2019 & Meeting with elderly residents & 14 \\
\hline 17 April 2019 & $\begin{array}{c}\text { Focus group interview - staff as } \\
\text { proxies }\end{array}$ & 12 \\
\hline 1: Not applicable & \multicolumn{2}{c}{}
\end{tabular}

a memory centre, day rehabilitation, senior housing, group housing, a family centre, and physiotherapy facilities. There is a small garden in the back, with a rather busy street on the building's front. As shown in Figure 1, the garden offers free entrance to visitors. However, this also means that the residents are free to walk outside of the garden perimeters. Thus, unsupervised visits to the garden by the residents are not allowed.

All residents $(n=14)$ at the dementia care residence were in severe stages of dementia and had been living at the residence for 1-2 years. Overall, twelve caregivers (hereafter called staff) work at the institution to take care of the residents during the day (ten people) and night (two people). An occupational therapist and a nurse also work there during the daytime. The occupational therapist is responsible for choosing and implementing different aids supporting residents' daily lives while the nurse is responsible for medication. In this study, we worked very closely with the occupational therapist and the head of the residence.

\section{Data collection}

We aimed to collect residents' needs regarding digital technologies and actively involve them in the needs eliciting process. Based on previous research findings, we knew that it is challenging to actively include people with severe dementia

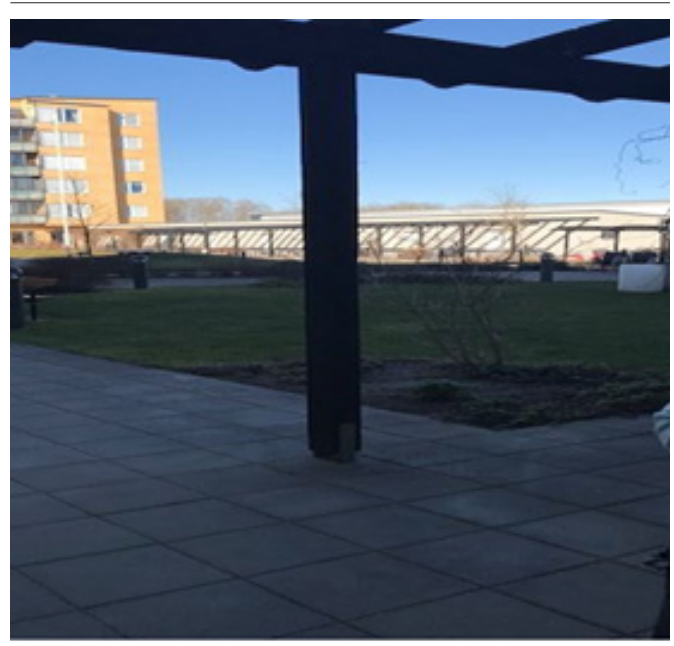

Figure 1. The garden. in different stages of digital technologies development. We also knew that involving their closest caregivers is beneficial in eliciting the needs of people with dementia. Therefore, we have decided to include the residents, staff, and relatives in collecting the needs of people with dementia regarding which digital technologies should be implemented at the dementia care residence. The staff were permanently employed, worked daily, and had many years of experience at the dementia care residence. They had basic technological skills and could operate daily technologies (e.g. smartphones). However, they did not have experience with more advanced technologies (e.g. monitoring/tracking technologies) in regards to dementia care (besides alarms). The data collection process spanned five months, from February to June 2019. The empirical material consists of focus group interviews, notes from meetings with key informants, and pictures taken during the residence visit (Table 1).

The data collection was conducted in four steps: (1) focus group interview with staff, (2) focus group interview with relatives, (3) informal discussions with residents, (4) observations of the environment and common areas within the residence and (5) focus group interview with staff as proxies. The first two data collection steps included two focus group interviews, one with the staff (12 interviewees) of the dementia care residence, and one with relatives (4 interviewees) of residents. We described our research's purpose to participants during the two focus group interviews and explained the type of questions we would like to focus on. After the introduction, we divided participants into smaller groups (4-5 in each group) to initiate the focus group interviews. Each group was assigned to one researcher, who asked questions and took notes. The questions focused on the challenges and needs they experience in taking care of residents to identify areas where digital technologies would improve residents' quality of life. The researchers always asked "why" to deepen their understanding and reveal the reasons for the experienced problems and needs. Both focus group interviews lasted about an hour. The focus group interviews immersed us in the context where the study was taking place (Allan, 2002) and helped us understand the practical problems experienced at the residence. Focus group interviews help generate consensus views and more varied responses since each participant's ideas are challenged or stimulated by others (Oates, 2005). As support to collect data from the residents, we initially suggested using small user diaries (Dickinson et al., 2007) where residents could describe their everyday life. Based on these diaries, we wanted to 


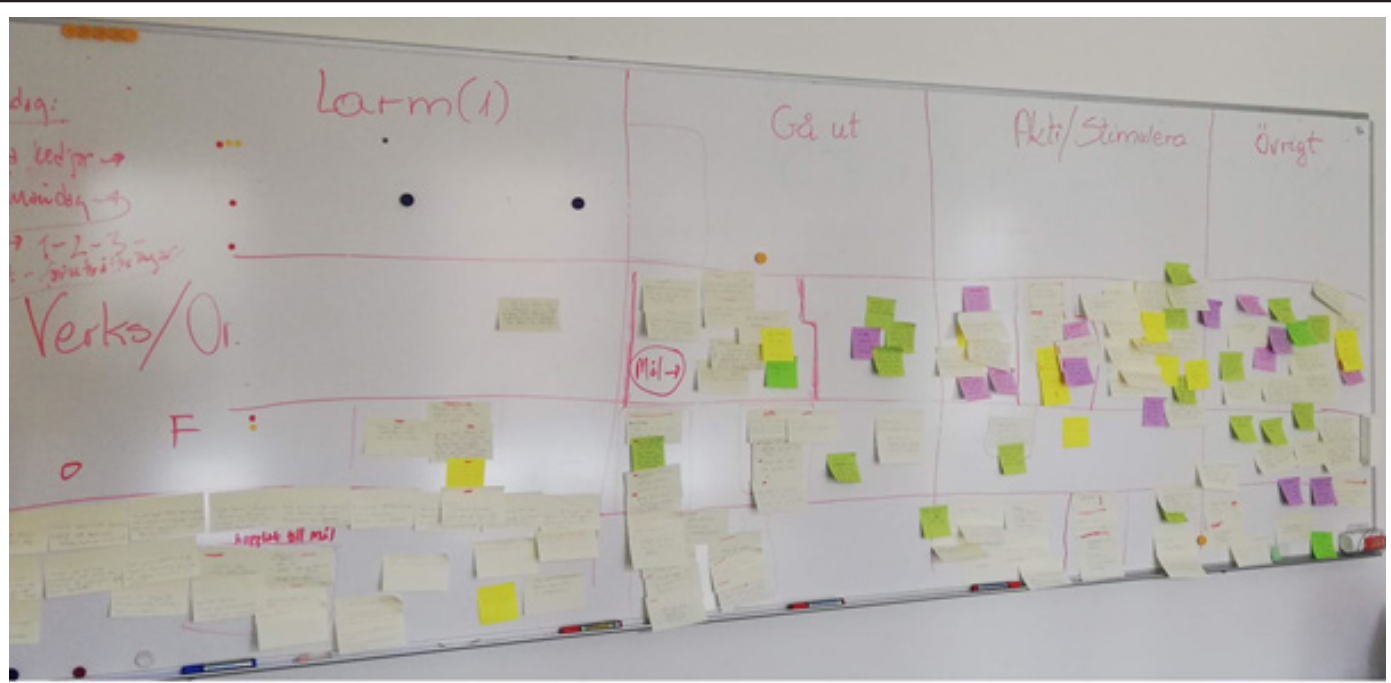

Figure 2. The post-it analysis (each colour represents a different group).

develop probes (as a supplementary data collection step) used in our informal discussions with the residents because they are a common tool for eliciting needs from people with dementia (Brown et al., 2014; Wherton et al., 2012). Probes are usually a collection of assignments such as diaries or through pictures in which the users can in a playful way record their experiences and express their thoughts and ideas (Mattelmäki, 2006). Probes are an alternative way of collecting material from people with disabilities (and in this case people with dementia). However, the head of the unit and the occupational therapist rejected these ideas, arguing that residents with severe stages of dementia would not be capable of writing down their thoughts or answering abstract questions. Hence, we respected their opinions and did not further pursue that venue. Thus, we decided to conduct informal interviews and participating in observation in the residents' life settings. We were provided with a guided tour of the residence and the areas around the property where the elderly residents also had access. We visited the garden (Figure 1), and the common areas where the elderly residents could also use (e.g. dining and coffee room). Alongside the garden and common areas, we were guided in a way that allowed us to understand the areas that the elderly residents and staff have to go through if they wanted to go from the residence to the garden (e.g. stairs, elevator, different floors). All this provided us with an understanding of the social and environmental factors that would later come into play when identifying possible digital technologies to work in these settings.

The meeting took place in a suitable and accessible for the residents' area in dementia care (Prior et al., 2013), during a coffee break (14 participants). During the meeting, one researcher asked the questions and the other notes. Since we did not want to confuse asking difficult questions, we refrained from talking about technology and instead focused on residents' everyday life experiences and on what they like and do not like. The researchers' questions during that meeting revolved around the activities within the dementia care residence, the residents' everyday life, and residents' interaction with the staff. We aimed to find digital technologies that would address the identified needs/problems based on the information. The meeting with the residents lasted about 30-45 minutes. To complement the data collected at the meeting with the residents, we also conducted focus group interviews with the staff (12 interviewees) as proxy informants (Gruber-Baldini et al., 2012), taking on the role and speaking for the elderly residents (Sjölinder et al., 2017). The focus group interviews with the staff as proxies took place after the researchers met with the residents.

\section{Data analysis}

The collected data were analyzed in two stages. First, the researchers identified needs from the collected data by focusing on needs and problems expressed by the relatives, staff, and residents during the data collection sessions and the observations we made during the department visit. Each need/problem was connected to a stakeholder group during the data collection sessions (the answer to the why question). Second, all identified needs were categorized into groups dealing with similar issues (e.g., a new alarm system to react in case of an emergency that does not increase stress levels at the residence or the possibility for the elderly to go out) for each stakeholder group. For the categorization, all identified needs were written down on post-its. Different colours were used to ensure traceability for the stakeholder 
groups. Light yellow was used for the staff, green/ purple for the relatives, and yellow for the elderly residents with dementia (Figure 2).

The categorization was done in two sessions, where the researchers worked together with representatives for the care residence (head of the unit and occupational therapist). Several categories emerged, but the care residence representatives pointed out three of them as most important to address (on the horizontal side of Figure 2): (1) reducing stress related to the existing alarm system, (2) the residents' possibility to go outside, and (3) stimulation/activities for the residents. As we applied a holistic approach (considering environmental and social aspects) in our data collection, we noticed that not all of the needs could be addressed by solely implementing digital technologies - some of the needs concerned changing work processes or property management (vertical side of Figure 2). Therefore, we placed the needs in three categories (work processes/organization, property management, and technology). In this way, we created a matrix of nine categories as illustrated in the result section. Examples from the analysis are shown in the result section.

The results from the analysis were explained and presented to the staff during an hour meeting. The staff agreed with our interpretations and prioritization of the problems and needs experienced at the residence. We also jointly decided to inform the landlord about the problems/needs identified in relation to the property.

\section{Ethical considerations}

This study is in line with the ethical recommendations of the Swedish Ethics Review Authority. In that sense, this study does not use personal information that can directly or indirectly be connected to a person and does not involve a physical intervention or a method to affect the research person physically or mentally (Riksdagsförvaltningen, 2003: 460). To that end, all interviewees were given a form in which the study details were explained. The interviewees maintained their anonymity throughout the study and could withdraw whenever they wished, without explanation. Regarding our visit to meet the elderly residents, we obtained consent from the head of the unit and the relatives of the elderly residents. During the focus group interviews and the meeting with the elderly residents, we did not use any recording devices to prevent possible identification issues; thus, all quotes used in this article were derived from the researchers' notes. Additionally, for the meeting with the elderly residents, we introduced ourselves and asked (oral and visual consent) for their permission to sit and join them in their coffee break.
During the meeting, the researchers also focused on the well-being of elderly residents. When noticing discomfort, the researchers would pause the conversation and provide the space needed to allow the residents to feel comfortable again (respecting boundaries).

\section{RESULTS - IDENTIFYING NEEDS FOR POTENTIAL DIGITAL TECHNOLOGIES}

This section reports on needs identified during the data collection sessions with the different stakeholder groups.

\section{Staff needs}

The staff unanimously stated that their top need was for more time. Time was crucial since it would allow staff to create more activities for the residents, thus tackling the under-stimulation problem that they reported. In the focus group interview, the staff mentioned that three people are usually responsible for taking care of 14 residents on rotation. This does not allow room for anything other than what was planned for the day. Additionally, the staff mentioned that they do not manage everything since practical issues, such as preparing breakfast or other things, take a long time: "It is hard to find common activities for the residents since there is not enough time and not enough activities".

According to the staff, the lack of activities created a restraining feeling among residents, increasing their anxiety over time (something the staff described as a stressful working and living environment), and subsequently increased the staff's workload since they had to make the residents feel calm again. In such events, the staff suggested that the use of a robotic companion combined with music would have a two-fold benefit, as it would reduce the staffs' workload and help calm down the residents. According to the staff, such a solution could also be used for residents who lack physical affection. Other examples of 'entertainment and reminiscence' aids such as photo albums, music, games, films, karaokestyle apps, and VR could also be used. Regarding the lack of activities, the staff mentioned that going outside was the most problematic activity and the one that the residents enjoyed the most. This need was challenging to address due to time limitations, staff shortages, and restrictions regarding the doors, which are always locked, to prevent residents from falling down the stairs or getting lost. Here the suggested digital technologies were different kinds of GPS devices, easyto-use phones, and geo-fencing connected to a system allowing the staff to locate the residents outside the building. However, the staff also emphasized the need to change work processes and re-paint the doors and corridors to decrease the residents' confusion when exiting and re-enter- 


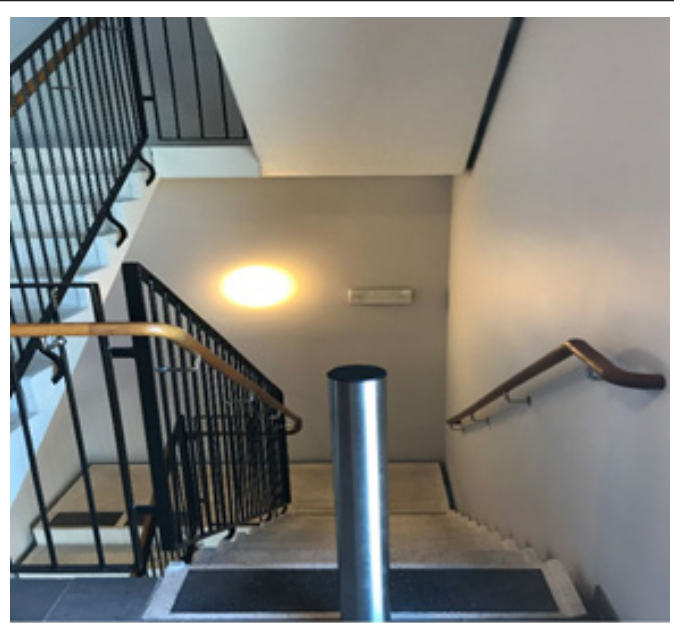

Figure 3. Stairs.

ing the care residence. The staff experienced the existing alarm solution (the current system and devices) implemented at the residence as a big problem. The alarms created a feeling of distress among residents due to the loud noises. The staff mentioned several alarms going off without any real reason; for example, when a blanket would drop on the floor at night, the alarm would go off and wake up the residents. Also, the alarms disturbed the residents' peacefulness, which the staff strived to maintain: "The sound of the alarm is annoying and makes the residents worried and we have to calm them down".

Maintaining peacefulness was highlighted, along with stress, which leads to reduced well-being for residents. Overall, the staff's goal was to maintain peacefulness, avoid creating additional workloads, and further reduce the residents' time allocated to activities. Another area the staff mentioned as problematic is monitoring. For example, they noted that they would like to know when residents get out of bed during the night:

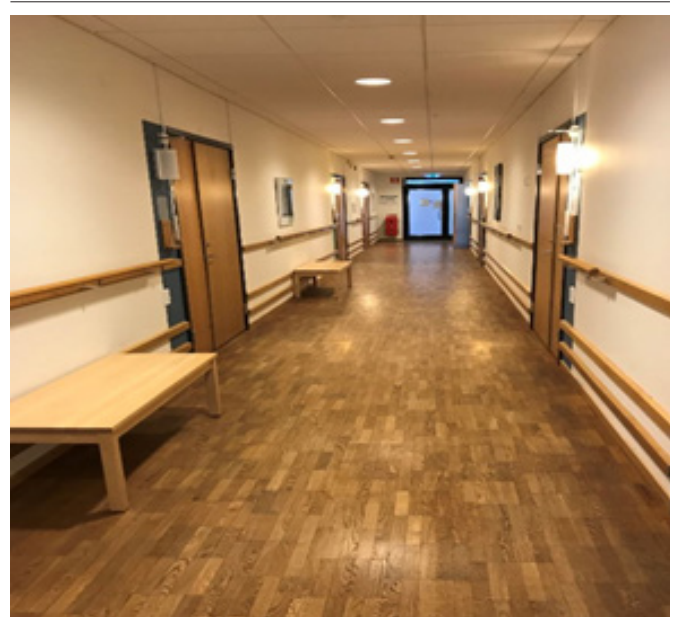

Figure 4. Hallway to residents' rooms.
"Want to know why you get up, is it for a toilet visit that you manage yourself or is it a fall?".

The staff also stated that they do not want to make the residents feel monitored, but instead provide them with a sense of independence. Regarding monitoring, the staff also stated that the alarms pointing out a certain location of a fall or incident are usually inaccurate, as they show that something is happening at point $\mathrm{A}$ but, by the time the alarm goes off, the person who triggered it has already moved to point $B$. The staff also pointed out that sometimes the alarm sound is disturbing or acute, which does not always correspond to the severity. This suggests that different alarms can be used for other occasions and that they can be changed to smoother sounds at night, so they do not disturb the residents while sleeping.

\section{Needs for relatives}

The relatives were concerned that the staff workload could lead to a reduced quality of care. One of them stated: "We do not experience any problems, it is the staff who has to deal with the problems". Another issue mentioned by the relatives was the lack of activities. According to them, their loved ones were under-stimulated and often seemed inactive. "I would like to see more activities, I do not like watching my man sitting on the wheelchair for so long", "I have not seen any of the residents doing any physical activities to keep being active".

The relatives agreed that going out brought joy to their loved ones. However, due to their dementia, they cannot go out unattended. Therefore, going out was limited and increased the feeling of restrainment, as also described by the staff. Regarding the quote about physical activities, the unit head stated that residents have planned physical activities and suggested that relatives could be updated through a mobile phone application that would let them know about their loved ones' activities. Receiving updates and information about the lives of their loved ones is something that all relatives positively agreed on, since no one gets such information: "No one informs about what is happening", "We know nothing about what is happening during the day". Another concern raised by relatives was the lack of communication with their loved ones, stating that communication needs to take place face-to-face; otherwise, the dementia stage makes it impossible to communicate through a mobile phone or any other technology. "I cannot contact my loved one because they cannot use a mobile phone, so it always needs to be faceto-face communication", "She is afraid of the telephone, she can reply but cannot ring". However, the relatives agreed that it would be a good idea to communicate using tablets where both 
parties (with the help of the staff) would be able to interact and communicate through a camera.

Lastly, in combination with the matter of communication, the relatives also raised a concern regarding the residents' feeling of loneliness, due not solely to the lack of communication, but overall to the lack of activities, going out, etc.

\section{Needs of elderly residents with dementia}

Our observations highlighted several issues regarding the navigation within the dementia care residence. First, each floor's entrances looked similar, making navigation within the building somewhat confusing for both staff and residents. Second, the elevator had no markings for each floor button. If one chose not to use the elevator, the stairs posed a risk for falls as there were no increased safety measures, only a railing on the side (Figure 3). Additionally, each residents' room's doors were the same in the hallway within the residence, with no unique identifiers. (Figure 4).

We also visited the garden the residents could use for some outdoor activities; however, this was not fenced, posing an increased risk of losing a resident. As mentioned, these needs could be addressed by different kinds of GPS devices, easy-to-use phones, and geo-fencing connected to a system allowing the staff to locate residents outside the building, in combination with changes in the building. When we met with the residents, they mentioned that they enjoy living in the dementia care residence. However, they stated that they would like more activities and to be able to go outside more often. The activities mentioned included watching television and listening to music. Furthermore, in our visit, we saw that the residents spent much time in silence if no one engaged in conversation with them. Lastly, during the meeting with the residents, we noticed several people holding on to physical objects, and in one case, a researcher was asked by a resident to have his handheld. Even though physical affection was not something that the residents described to us, it was rather apparent from their actions. To confirm our observation, we asked the unit's head about this issue, which positively replied. The need could be addressed by purchasing digital technologies with therapeutic effects, such as pet robots or simulated presence therapy.

\section{Needs of elderly with dementia - staff as proxies}

When we asked the proxies about what activity the residents would enjoy more often, they all agreed that what they would enjoy most is going outdoors. However, they stated that this is hard to arrange for sole individuals who want to be outside due to staff shortages. Some residents also feel confused, just waiting in front of the door to go back home. Thus, the doors remained locked, adding to the residents' feeling of restraint. Going outside can be rather problematic since the residents live on the third floor of the building, meaning a high risk of falls from the stairs. Although an elevator exists, not everyone knows how to use it, and since all floors look alike, it is even more challenging for residents to navigate and know where to go. The staff (proxies) also mentioned the garden, which is open to the residents; since there are no fences, however, there is a high risk of them going out and getting lost. Also, the residents had no means of communicating with the staff in case of harm or any other incident. "We are worried about the residents going out by themselves and getting lost, or injuring themselves since there is no way of communicating with them".

When asked about the residents' interests, the proxies reported that there are people who enjoy watching sports channels on television, yet complained that channels' offer is rather limited. Animal companions have also been something that works well with the residents - together with a relatives' visit. However, it is hard to maintain living animals around the residence since that would increase the staff's workload. "It is hard to have living animals around, hard to maintain, especially if they destroy any furniture or other items, which can become expensive too". Nevertheless, the proxies mentioned that robotic companions would possibly have the same calming effect on residents as living animals.

Another reported interest was listening to music, but no multi-media machine was functioning. Other activities included a training bike to exercise, painting, reading, and browsing newspapers. Lastly, the proxies pointed out several problems with the alarms used. They agreed that the residents would sometimes become worried or afraid when someone opened the doors to check on them during night checks. In addition to disturbing them, the alarms would also cause residents to feel stressed and worried whenever they went off. On certain occasions, residents would also pick up portable alarms (moving alarms) and move them somewhere else because of their "ugly" design. These alarms usually have a bleeping red light, making residents think either that the alarm is a robot or that something is starting to burn because of the red colour. There is a clear need for new alarms that could reduce these problems.

\section{Summarized needs in relation to the categorization}

First, this section summarizes the needs identified previously and puts them accordingly to the categories provided in the data analysis section (Table 2). Then, we provide examples of digital technologies and other solutions that should 
Table 2. Analysis of identified needs ( $S=$ Staff, $R=$ Relatives, $E R=$ Elderly Residents, SaP $=$ Staff as Proxies).

\begin{tabular}{|c|c|c|}
\hline $\begin{array}{l}\text { Needs / } \\
\text { Categories }\end{array}$ & $\begin{array}{l}\text { Reducing stress related to the } \\
\text { existing alarm system }\end{array}$ & $\begin{array}{l}\text { The residents' possibility to go } \\
\text { outside }\end{array}$ \\
\hline $\begin{array}{l}\text { Property } \\
\text { management }\end{array}$ & $\begin{array}{c}\text { S: Residents wake up when staff } \\
\text { comes to the room to respond to } \\
\text { the alarms because the doors are } \\
\text { weighty and loud. }\end{array}$ & $\begin{array}{l}\text { S: The staff emphasized the need to SaP: The garden, which is } \\
\text { re-paint the doors and corridors to open to the residents; since } \\
\text { decrease the residents' confusion there are no fences, there is a } \\
\text { when exiting and re-entering the care high risk of them going out } \\
\text { residence. } \\
\text { and getting lost. }\end{array}$ \\
\hline
\end{tabular}

SaP: The doors remained locked, adding to the residents' feeling of restraint. Going outside can be rather problematic since the residents live on the third floor of the building, meaning a high risk of falls from the stairs.

SaP: Residents enjoy watching sports channels on television. Furthermore, animal companions also work well with the residents, and they help in reducing stress.

SaP: All floors look alike, it is even more challenging for residents to navigate and know where to go.

Work process/ S: Maintaining peacefulness, to S: The most problematic activity due Organization avoid creating additional workloads, and further reduce the time allocated to activities for ER: they stated that they would like the residents. to go outside more often.
S: Time is required to conduct activities.

R: Staff workload could lead to a reduced quality of care and amount of activities.

ER: They would like to have more possibilities for activities.

\section{Technology S: The staff mentioned several S: GPS devices, easy-to-use phones,} alarms going off without any real and geo-fencing connected to a

S: The use of a robotic reason. system allowing the staff to locate the
residents outside the building.

S: The staff also pointed out that companion combined with music would have a two-fold benefit, as it would reduce the staffs' workload and help calm down the residents. disturbing or acute, which does not always correspond to the severity.

SaP: the alarms would also cause residents to feel stressed and worried whenever they went off.

R: Receiving updates and information about the lives of their loved ones is something that all relatives positively agreed on since no one receives such information

SaP: residents would also pick up portable alarms (moving alarms) and move them somewhere else because of their "ugly" design.

SaP: Residents have no means of communicating with the staff in case of harm or any other incident.

SaP: Alarms usually have a bleeping red light, making residents think either that the alarm is a robot or that something is burning due to the red colour.

SaP: Robotic companions would possibly have the same calming effect on residents as living animals.

be considered to tackle the identified problems within the different categories (Table 3).

Table 2 provides an overview of how the identified needs fall under the different categories (e.g. Property, Organization, Technology). Since we are holding a socio-technical perspective, we did not solely identify technological needs but also needs falling under work processes and property management. Therefore, we have addressed socio, technical and environmental aspects.

Table 3 presents some examples regarding proposed digital technologies that could address some of the identified needs shown in Table 2. Starting with the alarm systems, we suggested that monitoring systems (such as cameras or sensors) could reduce the stress of the residents 
Table 3. Examples of proposed solutions.

\begin{tabular}{|c|c|c|c|}
\hline $\begin{array}{l}\text { Needs / } \\
\text { Categories }\end{array}$ & $\begin{array}{l}\text { Reducing stress related to the } \\
\text { existing alarm system }\end{array}$ & $\begin{array}{c}\text { The residents' possibility to go } \\
\text { outside }\end{array}$ & $\begin{array}{l}\text { Stimulation/activities for the } \\
\text { residents }\end{array}$ \\
\hline Technology & $\begin{array}{c}\text { Monitoring system (camera or } \\
\text { sensor). }\end{array}$ & $\begin{array}{l}\text { GPS-device localization system, } \\
\text { with the possibility to contact } \\
\text { staff in case of emergency. }\end{array}$ & $\begin{array}{l}\text { Interactive projector } \\
\text { technology supporting } \\
\text { interaction between the } \\
\text { residents and the caregivers. }\end{array}$ \\
\hline & & & $\begin{array}{l}\text { Robotic companions } \\
\text { supporting residents and } \\
\text { promoting a less stressful } \\
\text { environment. }\end{array}$ \\
\hline
\end{tabular}

Work process/ Access control, who is allowed to Staff need to be able to operate Someone of the staff need to Organization check the logs, education, how can the system, charge the GPS be present at the table the data be used.

Using monitoring system that the staff could access from mobile phones, without the necessity to react on every (even false alarms) would create more time for the staff devices, ensure that the residents (education is needed), support take the GPS-device with them. relatives using this aid.

to do other things and reduce the level of stress caused by the loud sound of the alarms.

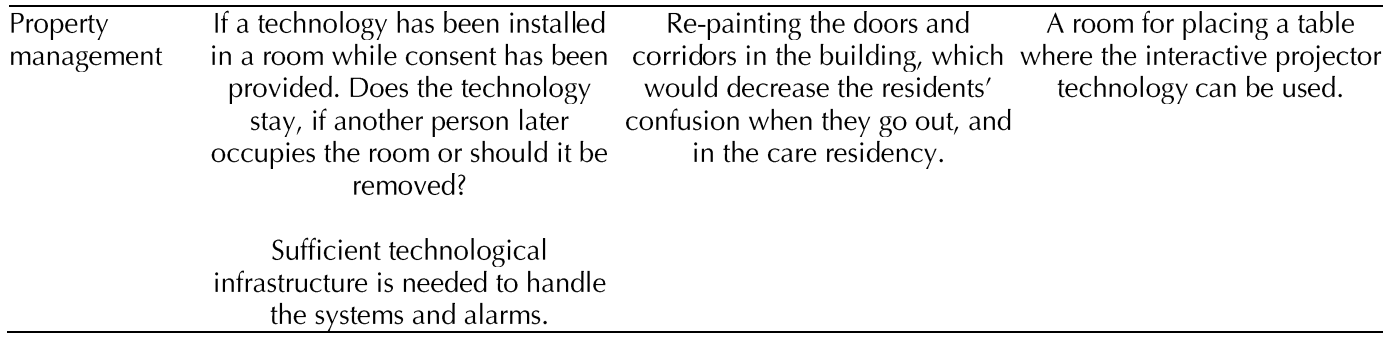

for example when the staff enters their rooms to check on them at night. However, as we argue in the introduction, we do not hold just a technocentric perspective. Thus we proposed solutions on how the digital technologies should work together with the work processes (organization) and the property.

In regards to going outside, we proposed a GPS-device that would help the staff locate the residents, and provide residents with a degree of freedom and independence. Nevertheless, tracking technologies alone do not provide a holistic solution. Thus additional changes should also be made on a property level (re-painting of the walls), but also the staff would need to be trained to operate such devices.

Regarding the residents' stimulation, we suggested the use of an interactive projector technology called Toveltafel, which promotes interactions between the residents and staff. However, this means that time is required from the staff to operate the technology and a room or small space is needed to place the technology. Lastly, we also suggested the use of robotic companions (as was already mentioned by the staff), which could help residents feel less stressed and that would not require the staff to invest a lot of time.

\section{DisCUSSION AND CONCLUSION}

This study aimed to identify possible digital technologies to cover people with dementia's needs regarding daily living activities within the dementia care residence. However, we want to state that this study does not implement any technologies at this stage but provides suggestions that would help to address the needs identified in the interviews. This study contributes to research within dementia care and support residences, which, as Meiland et al. (2017) describe, is under-researched. As described in the previous sections, the most prevalent discussed needs regarded the insufficient alarm system, going out, and activities regarding stimulation and activation of the residents (Table 2). A few examples of how digital technologies were suggested based on the analysis are shown in Table 3. Based on the analysis, three implications emerged:

First, systematically analyzing needs regarding daily living activities within a dementia care residence allowed us to understand the existing problems and their consequences better. We focused on and prioritized the most critical digital technologies that could address the dementia 
care residence problems (such as alarms and lacking the possibility to go outside). In contrast to previous studies (Lazar et al., 2017; Lindsay et al., 2012; Mor'an and Meza Kubo, 2009; Cohene et al., 2005), we approached the dementia care residence without any pre-determined technology in mind. Thus, we were able to identify the solutions that would be most needed in a specific context. Such an approach may lead to better strategic choices and implementation of digital technologies, avoiding costly investments in unneeded solutions. Having said that, the identified digital technologies are in line with previous research by Lorenz et al. (2019), which recalled similar digital technologies, such multimedia devices, which they refer to as therapeutic interventions, and GPS. Furthermore, our study contributes to previous research by discussing relevant functionality features for such devices. For instance, according to the staff, GPS alarms need to offer adjustable functions such as the possibility to call the staff in case of emergency (if the resident is unable to do so), a fall detection function, reducing/increasing the volume of the alarm, its tone, frequency, etc. Additionally, they should also be combined to open different doors within the property since the doors are locked.

Secondly, it was clear that implementing solely digital technologies could not alleviate experienced problems or address the identified needs. The analysis shows that maintaining a purely technological focus could lead to solutions that would not work or benefit the dementia care residence (Table 2). One such example could be identified in the category of "going out". Our analysis showed that digital technologies, such as GPS, would need to be complemented by organizational processes and property changes. As illustrated in Table 3, it was clear that a GPS solution would be optimal to allow the staff to keep track of the residents when they were outside. However, this would not solve the residents' problem regarding going outdoors since, as mentioned, there were other safety issues (falling from stairs) that needed to be addressed. Furthermore, the floors were all similar, adding confusion, and the elevator did not have any different markings or colours for floors. Therefore, as discussed, the GPS would only solve part of the existing problem. This conclusion is in line with (Lazar et al., 2017), who emphasize the importance of considering and understanding "socio-material arrangements", including technological and social aspects. Together, these participate in the process of meaning-making in a specific context.

Furthermore, this study also confirms contemporary research regarding the use of particular types of digital technologies such as robotic companions, positively affecting people with dementia
(Pike et al., 2020). A need for physical affection was observed during our meeting with the residents, which made it clear that such technologies would positively impact the residents' lives. Other technologies that would benefit both carers and residents were, as mentioned, GPS, which would give the residents a degree of freedom and allow the carers to monitor the residents without being next to them, thus actively working on other tasks. Cameras and sensors would also alleviate certain difficulties that would arise during the night, where the carers would enter the resident's rooms to check on their well-being but would ultimately disturb them. However, when implementing such technologies, one should not forget about the ethical issues surrounding privacy and surveillance (Niemeijer et al., 2010). Multi-media devices could also assist the residents with activities (Meiland et al., 2017) within the residence, which was also discussed in the interviews. Nonetheless, to carry out activities with the residents and the carers, there was a need for a better time allocation, which is where changes in the work processes should occur.

Additionally, involving people with severe stages of dementia as active participants in the requirement collection of technology appears quite problematic. In contrast to previous studies (see related research chapter), we actively pursued the residents' involvement in this study, following the suggestions of Whitlatch and Menne (2009). However, we did face several challenges in doing so. As mentioned in the method section, we could not use small user diaries and further on a probe we wanted to develop to meet with residents based on the data collected from the focus group interviews with staff and relatives. Even though the head of the unit reported that the residents would not be able to participate in the activities that we suggested (due to their stage of dementia), we believe that with the staff's active involvement, such data collection would have been possible a certain degree. In conclusion, we believe that a combination of methods (probes, participatory observations, and proxy informants) is needed to involve people with severe stages of dementia as active participants in the design of technology. However, during our meeting with the elderly residents, we noticed a variance in their dementia stage. Some of the residents could interact with us naturally, while others could not articulate themselves. On another note, our findings should not discourage researchers from actively including people with late dementia in their studies, since the literature describes they offer unique feedback (Wolters et al., 2016). Hence, our findings are in line with previous literature (Suijkerbuijk et al., 2019), which calls for more research on methods that would support engaging and empowering people with dementia in 
designing technologies and identifying needs by involving people with dementia.

Finally, we would like to share some reflections regarding the involvement of the staff in the problem/needs identification and the choice of digital solutions. Usually, the staff are not included in decision-making processes concerning their work situation and work environment because of their rather low work status. Therefore, involving the staff in the decision-making process concerning digital solutions made them feel valuable and appreciated as their opinions would possibly impact (positively) their work. Additionally, as we were considered external researchers (not working in the dementia care residence), the staff felt that they were able to express their opinions freely and be in control of the process. They felt important and listened to, which made them feel empowered by providing ideas about the solutions that would be implemented. As a result, the staff were supportive and keen to carry out the recommended changes to enhance the elderly's living patterns despite their high workload. Last, having a focus on social, environmental, and technical aspects, we noticed that some improvements and adjustments could be made even before the digital solutions were in place. For instance, by painting the floors and adding extra safety measures, some residents (with mild to moderate dementia) were able to go outside more often without the staff's help, as they could find their way back to their residence.

\section{Limitations}

This study is context-specific, meaning that we cannot claim that the results could be easily transferred to another residence. However, some of the identified problems could be identified in other places, making our results valuable in similar contexts. Another limitation of this study is the amount of time the researchers interacted with the residents. When involving people with dementia as active participants, it is important to build trust with them (van Baalen et al., 2011). However, we did not have such capability; thus, time being a limitation of our study. Furthermore, dementia is an umbrella term for different forms of dementia such as Alzheimer's disease, Frontotemporal dementia, or dementia with Lewy Bodies. This study brought together all different forms of dementia. Hence, the findings may vary when considering different types of dementia.

\section{References}

Allan, K. (2002). Working with staff to include people with dementia in research. The perspectives of people with dementia: Research methods and motivations, 117-137.

Alzheimer's Association (n.d.). What is Dementia?. Retrieved from https://www.alz.org/alzheimers-dementia/what-is-dementia.

Blasco, R., Blanco, T., Marco, A., Berbegal, A., \& Casas, R. (2014). Needs identification methodology for inclusive design. Behaviour \& Information Technology, 35(4), 1-36.

Brown, M., Tsai, A., Baurley, S., Koppe, T., Lawson, G., Martin, J., ... \& Arunachalam, U. (2014). Using cultural probes to inform the design of assistive technologies. In International Conference on HumanComputer Interaction (pp. 35-46). Springer, Cham.

Cahill, S., Macijauskiene, J., Nygård, A. M., Faulkner, J. P., \& Hagen, I. (2007). Technology in dementia care. Technology and Disability, 19(2-3), 55-60.

Cohene, T., Baecker, R., \& Marziali, E. (2005). Designing interactive life story multimedia for a family affected by alzheimer's disease: a case study. In CHI'05 extended abstracts on Human factors in computing systems (pp. 1300-1303).

Denscombe, M. (2014). The good research guide: for small-scale social research projects. McGraw-Hill Education (UK).

Dickinson, A., Arnott, J., \& Prior, S. (2007). Methods for human-computer interaction research with older people. Behaviour \& Information Technology, 26(4), 343-352.

Eason, K., Waterson, P., \& Davda, P. (2015). The sociotechnical challenge of integrating telehealth and tel-

ecare into health and social care for the elderly. In Healthcare administration: concepts, methodologies, tools, and applications (pp. 1177-1189). IGI Global.

Ertner, M. (2019). Enchanting, evoking, and affecting: the invisible work of technology implementation in homecare. Nordic Journal of Working Life Studies, 9.

Eurostat (n.d.) Population age structure by major age groups, 2007 and 2017. Retrieved from https:// ec.europa.eu/eurostat/statistics-explained/index. php?title=File:Population_age_structure_by_major_age_groups,_2007_and_2017_(\%25_of_the total_population).png

Frennert, S. (2020). Approaches to welfare technology in municipal eldercare. Journal of Technology in Human Services, 1-21.

Gruber-Baldini, A. L., Shardell, M., Lloyd, K. D., \& Magaziner, J. (2012). Use of proxies and informants. In The Epidemiology of Aging (pp. 81-90). Springer, Dordrecht.

Hagethorn, F. N., Kröse, B. J., de Greef, P., \& Helmer, M. E. (2008). Creating design guidelines for a navigational aid for mild demented pedestrians. In European Conference on Ambient Intelligence (pp. 276-289). Springer, Berlin, Heidelberg.

Holbø, K., Bøthun, S., \& Dahl, Y. (2013). Safe walking technology for people with dementia: what do they want?. In Proceedings of the 15th international acm sigaccess conference on computers and accessibility (pp. 1-8).

Holthe, T., Halvorsrud, L., Karterud, D., Hoel, K. A., \& Lund, A. (2018). Usability and acceptability of technology for community-dwelling older adults with mild cognitive impairment and dementia: a systematic literature review. Clinical interventions 
in aging, 13, 863.

Hubbard, G., Cook, A., Tester, S., \& Downs, M. (2002). Beyond words: Older people with dementia using and interpreting nonverbal behaviour. Journal of Aging Studies, 16(2), 155-167.

Kolkowska, E., Nöu, A. A., Sjölinder, M., \& Scandurra, I. (2016). Socio-technical challenges in implementation of monitoring technologies in elderly care. In International Conference on Human Aspects of IT for the Aged Population (pp. 45-56). Springer, Cham.

Kristoffersson, A., Kolkowska, E., \& Loutfi, A. (2014). Assessment of expectations and needs of a sensor network to promote elderly's sense of safety and security. In CENTRIC 2014, The Seventh International Conference on Advances in Human-oriented and Personalized Mechanisms, Technologies, and Services (pp. 22-28). International Academy, Research and Industry Association (IARIA).

Lazar, A., Edasis, C., \& Piper, A. M. (2017). Supporting people with dementia in digital social sharing. In Proceedings of the $2017 \mathrm{CHI}$ Conference on Human Factors in Computing Systems (pp. 2149-2162).

Lee, M. L., \& Dey, A. K. (2007). Providing good memory cues for people with episodic memory impairment. In Proceedings of the 9th international ACM SIGACCESS conference on Computers and accessibility (pp. 131-138).

Lindsay, S., Brittain, K., Jackson, D., Ladha, C., Ladha, K., \& Olivier, P. (2012). Empathy, participatory design and people with dementia. In Proceedings of the SIGCHI Conference on Human Factors in Computing Systems (pp. 521-530).

Liu, L., Miguel Cruz, A., \& Juzwishin, D. (2018). Caregivers as a proxy for responses of dementia clients in a GPS technology acceptance study. Behaviour \& Information Technology, 37(6), 634-645.

Lopes, P., Pino, M., Carletti, G., Hamidi, S., Legué, S., Kerhervé, H., ... \& Rigaud, A. S. (2016). Co-conception process of an innovative assistive device to track and find misplaced everyday objects for older adults with cognitive impairment: the TROUVE project. IRBM, 37(2), 52-57.

Lorenz, K., Freddolino, P. P., Comas-Herrera, A., Knapp, M., \& Damant, J. (2019). Technology-based tools and services for people with dementia and carers: Mapping technology onto the dementia care pathway. Dementia, 18(2), 725-741.

Lundälv, J. (2017). Användande av klassifikationen av ICF-en genomgång av förekomst av ICF i högre utbildning. Socialmedicinsk tidskrift, 94(5), 583-592.

Mattelmäki, T. (2006). Design probes. Aalto University.

Meiland, F., Innes, A., Mountain, G., Robinson, L., van der Roest, H., García-Casal, J. A., ... \& Kelly, F. (2017). Technologies to support communitydwelling persons with dementia: a position paper on issues regarding development, usability, effectiveness and cost-effectiveness, deployment, and ethics. JMIR rehabilitation and assistive technologies, 4(1), e1.

Morán, A. L., \& Meza-Kubo, V. (2009). Towards a teleassistance service for the cognitive stimulation of elders with cognitive decline. In 2009 International Conference on eHealth, Telemedicine, and Social Medicine (pp. 160-165). IEEE.
Mortenson, W. B., Pysklywec, A., Fuhrer, M. J., Jutai, J. W., Plante, M., \& Demers, L. (2018). Caregivers' experiences with the selection and use of assistive technology. Disability and Rehabilitation: Assistive Technology, 13(6), 562-567.

Niemeijer, A. R., Frederiks, B. J., Riphagen, I. I., Legemaate, J., Eefsting, J. A., \& Hertogh, C. M. (2010). Ethical and practical concerns of surveillance technologies in residential care for people with dementia or intellectual disabilities: an overview of the literature. International Psychogeriatrics, 22(7), 1129.

Oates, B. J. (2005). Researching information systems and computing. Sage.

Oishi, M. M. K., Mitchell, I. M., \& Van der Loos, H. M. (Eds.) (2010). Design and use of assistive technology: social, technical, ethical, and economic challenges. Springer Science \& Business Media.

Östlund, B., Olander, E., Jonsson, O., \& Frennert, S. (2015). STS-inspired design to meet the challenges of modern aging. Welfare technology as a tool to promote user driven innovations or another way to keep older users hostage?. Technological Forecasting and Social Change, 93, 82-90.

Pike, J., Picking, R., \& Cunningham, S. (2020). Robot companion cats for people at home with dementia: A qualitative case study on companotics. Dementia, 1471301220932780.

Prince, M., Bryce, R., \& Ferri, C. (2011). The benefits of early diagnosis and intervention. World Alzheimer Report, 2011.

Prior, S., Waller, A., \& Kroll, T. (2013). Focus groups as a requirements gathering method with adults with severe speech and physical impairments. Behaviour \& Information Technology, 32(8), 752-760.

Rashidi, P., \& Mihailidis, A. (2012). A survey on ambientassisted living tools for older adults. IEEE journal of biomedical and health informatics, 17(3), 579-590.

Regeringskasliet (n.d.) Digitaliseringsstrateging. Retrieved from https://www.regeringen.se/regeringens-politik/digitaliseringsstrategin/

Riksdagsförvaltningen Lag (2003:460). Om Etikoprövning av forsknings som avser människor svensk författningssamling 2003:2003:460 T.o.m SFS 2019:1144. Retrieved from https://www.riksdagen.se/sv/dokument-lagar/dokument/svenskforfattningssamling/lag-2003460-om-etikprovningav-forskning-som_sfs-2003-460

Schwartz-Shea, P., \& Yanow, D. (2013). Interpretive research design: Concepts and processes. Routledge.

Sjölinder, M., Scandurra, I., Nou, A. A., \& Kolkowska, E. (2017). Using care professionals as proxies in the design process of welfare technology-Perspectives from municipality care. In International Conference on Human Aspects of IT for the Aged Population (pp. 184-198). Springer, Cham.

SocialStyrelsen (2018). Nationella riktlinjer - Utvärdering 2018 Vård och omsorg vid demenssjukdom Sammanfattning med förbättringsområden. Retrieved from http://www.socialstyrelsen.se/Lists/ Artikelkatalog/Attachments/20812/2018-3-1.pdf

Socialstyrelsen (2017). En nationell strategi för demenssjukdom. Retrieved from: https://www.socialstyrelsen.se/publikationer2017/2017-6-4 
Span, M., Hettinga, M., Vernooij-Dassen, M., Eefsting, J., \& Smits, C. (2013). Involving people with dementia in the development of supportive IT applications: a systematic review. Ageing research reviews, 12(2), 535-551.

Stoukides, J. (2008). Creative and sensory therapies enhance the lives of people with Alzheimers. Rhode Island Medical Journal, 91(5), 186.

Suijkerbuijk, S., Nap, H. H., Cornelisse, L., IJsselsteijn, W. A., De Kort, Y. A., \& Minkman, M. (2019). Active involvement of people with dementia: a systematic review of studies developing supportive technologies. Journal of Alzheimer's Disease, 69(4), 1041-1065.

Tsertsidis, A. (2020). Challenges in the provision of digital technologies to elderly with dementia to support ageing in place: a case study of a Swedish municipality. Disability and Rehabilitation: Assistive Technology, 1-11.

Tsertsidis, A., Kolkowska, E., \& Hedström, K. (2019). Factors influencing seniors' acceptance of technology for ageing in place in the post-implementation stage: A literature review. International journal of medical informatics, 129, 324-333.

van Baalen, A., Vingerhoets, A. J., Sixma, H. J., \& de Lange, J. (2011). How to evaluate quality of care from the perspective of people with dementia: an overview of the literature. Dementia, 10(1), 112-137.

van Rijn, H., van Hoof, J., \& Stappers, P. J. (2010). Designing leisure products for people with dementia: Developing "the Chitchatters"game. American Journal of Alzheimer's Disease \& Other Dementias $®$, 25(1), 74-89.

Vichitvanichphong, S., Talaei-Khoei, A., Kerr, D., \& Ghapanchi, A. H. (2014). Adoption of assistive technologies for aged care: A realist review of recent studies. In 2014 47th Hawaii International Conference on System Sciences (pp. 2706-2715). IEEE.

Wherton, J., Sugarhood, P., Procter, R., Rouncefield, M., Dewsbury, G., Hinder, S., \& Greenhalgh, T. (2012). Designing assisted living technologies 'in the wild': preliminary experiences with cultural probe methodology. BMC medical research methodology, 12(1), 1-13.

Whitlatch, C., \& Menne, H. (2009). Don't forget about me! Decision making by people with dementia. Generations, 33(1), 66-73.

Wolters, M. K., Kelly, F., \& Kilgour, J. (2016). Designing a spoken dialogue interface to an intelligent cognitive assistant for people with dementia. Health informatics journal, 22(4), 854-866. 